\title{
Analysis of the distribution of assimilation products and the characteristics of transcriptomes in rice by submergence during the ripening stage
}

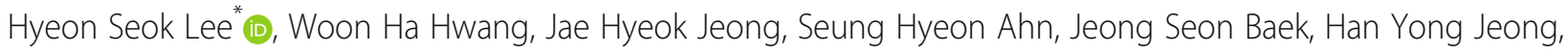
Hong Kyu Park, Bon II Ku, Jong Tak Yun, Geon Hwi Lee and Kyung Jin Choi

\begin{abstract}
Background: Research on the submergence stress of rice has concentrated on the quiescence strategy to survive in long-term flooding conditions based on Submergence-1A (SUB1A). In the case of the ripening period, it is important that submergence stress can affect the quality as well as the survival of rice. Therefore, it is essential to understand the changes in the distribution of assimilation products in grain and ripening characteristics in submergence stress conditions. However, such studies have been insufficient at the physiological and molecular biological levels.

Results: We confirmed that the distribution rate of assimilation products in grain was decreased by submergence treatment. These results were caused by an increase in the distribution rate of assimilation products to the stem according to escape strategy. To understand this phenomenon at the molecular level, we analyzed the relative expression levels of genes related to sucrose metabolism, and found that the sucrose phosphate synthase gene (OsSPS), which induces the accumulation of sucrose in tissues, was decreased in the seeds and leaves, but not in the stems. Furthermore, the sucrose transporter gene (OsSUT) related to sucrose transport decreased in the seeds and leaves, but increased in stems. We also analyzed the biological metabolic processes related to starch and sucrose synthesis, carbon fixation, and glycolysis using the KEGG mapper with selected differentially expressed genes (DEGs) in seeds, stems, and leaves caused by submergence treatment. We found that the expression of genes for each step related to starch and D-glucose synthesis was down-regulated in the seeds and leaves but upregulated in the stem.
\end{abstract}

Conclusion: The results of this study provide basic data for the development of varieties and corresponding technologies adapted to submergence conditions, through understanding the action network of the elements that change in the submergence condition, as well as information regarding useful DEGs.

Keywords: Submergence, Rice, RNA-sequencing, Physiology, Ripening stage

\footnotetext{
* Correspondence: gustjr1029@korea.kr

Crop Production \& Physiology Division, National Institute of Crop Science

Rural Development Administartion, Wanju 55365, South Korea
}

(c) The Author(s). 2019 Open Access This article is distributed under the terms of the Creative Commons Attribution 4.0 International License (http://creativecommons.org/licenses/by/4.0/), which permits unrestricted use, distribution, and reproduction in any medium, provided you give appropriate credit to the original author(s) and the source, provide a link to the Creative Commons license, and indicate if changes were made. The Creative Commons Public Domain Dedication waiver (http://creativecommons.org/publicdomain/zero/1.0/) applies to the data made available in this article, unless otherwise stated. 


\section{Background}

Rice is one of the most important crops in the world and it is crucial for the food security of many Asian countries [1]. Recently, an increase in the occurrence of abnormal weather phenomena and progressive global warming caused by the accumulation of greenhouse gases have resulted in damage to the growth and development of rice plants, which threatens food security [2]. Among the abnormal weather phenomena, the occurrence of heavy rainfall, exceeding the predicted maximum rainfall based on past weather data, is expected to increase the occurrence of submergence of agricultural land and seriously reduce the production of rice [3].

It is known that photosynthesis and respiratory metabolism are inhibited when the plant is submerged because gas diffusion is reduced by more than 10,000 -fold relative to that which occurs in the atmosphere, and light reaching the submerged leaves is attenuated by water [4,5]. When rice is completely submerged to the ends of its leaves and the supply of oxygen from the atmosphere has stopped, the pyruvic acid produced by glycolysis is not used as a substrate for normal aerobic respiration through the tricarboxylic acid (TCA) cycle, but rather as an anaerobic respiration substrate, such as alcohol fermentation, in which pyruvic acid is converted to ethanol by pyruvate decarboxylase and alcohol dehydrogenase [6]. In the case of anaerobic respiration, one molecule of glucose produces only approximately 2 ATPs compared with approximately 38 ATPs produced by aerobic respiration, resulting in an energy shortage because the respiratory substrate is quickly consumed $[7,8]$. If the anaerobic condition continues, the consumption of carbohydrates, such as monosaccharides and polysaccharides as the primary respiratory substrate is greatly increased, and protein is decomposed as a secondary respiratory substrate, such that it is greatly damaged or destroyed $[9,10]$. In addition, submergence can cause the degradation of chlorophyll, decrease of Rubisco activity, and damage to the photosynthetic apparatus, resulting in a large reduction in photosynthesis $[11,12]$. During the ripening period, such excessive consumption of the respiratory substrate and decrease in production and supply of assimilation products, may reduce the ripening rate, head rice ratio, and grain weight, which may result in decreased yield and quality.

Studies on submergence of rice have been conducted on a variety of topics, such as the quiescent strategy by the SUB1 gene, avoidance strategy by the SNORKEL 1 and 2 genes [8, 13], anaerobic respiration mechanism, hormone response [14], and remobilization of stored carbohydrates $[15,16]$. Primarily studies on the SUB1 gene, which regulates the submergence resistance characteristics and was first found in the submergence-resistant FR13A variety, have been performed [17-19]. Recently, to develop a new breeding program, efforts have been made to discover another quantitative trait locus (QTL) and various genes that could produce new effects in combination with the submergence resistance characteristics of the SUB1 gene [20]. Some intermediate tolerant varieties, such as IR64, carry the allelic variant SUB1A-2 and its derived tolerance near the isogenic line IR64-Sub1, which carries the SUB1A-1 allele, were used to compare the expression of nearly 2500 rice TF genes [21]. Additionally, paclobutrazol, which could significantly enhance rice seedling survival in submergence conditions by retaining a higher level of chlorophyll content and alcohol dehydrogenase activity, and decelerating the consumption of non-structure carbohydrate, was treated with rice. In total, 3936 differentially expressed genes(DEGs), which could enhance the submergence tolerance, were identified by transcriptomic analysis [22]. RNA-seq analysis was conducted in order to identify transcriptome characteristics for the difference in early growth between submergence tolerant and sensitive varieties of rice during the germination stage in submergence conditions. Candidate DEGs, such as OsTPP7, HXK7, and PGM, which could affect early growth under submergence conditions were selected [23]. Like these studies, transcriptome analysis studies related to submergence stress have been conducted recently. However, there is insufficient research at the physiological and molecular levels on this subject during the ripening stage.

In this study, we analyzed the effects of submergence treatment on the distribution characteristics of assimilation products during the ripening stage, and selected the useful genes that exhibited a difference in expression in the seed, stem, or leaf organs. In addition, basic information that could be used to develop material and DNA markers for breeding adapted varieties with submergence resistance characteristics by precisely identifying the genetic factors that characterize the necessary traits during the ripening stage.

\section{Results}

Distribution of assimilation products caused by submergence treatment during the ripening period

Nonstructural carbohydrates (NSCs), such as starch and soluble sugar, accumulated in the stem and leaf sheath before the heading date, and these NSCs accounted for approximately $30 \%$ of the energy source during ripening after heading $[24,25]$. In particular, when photosynthetic efficiency is decreased under environmental stress conditions, such as drought and salt stress, the use of the stored NSCs before heading would be an even more important factor in ripening [26]. In addition, the supply of oxygen to the plant was not smooth under the submergence condition, such that anaerobic respiration occurred, which caused energy production efficiency to drop sharply and 
eventually resulted in excessive consumption of respiration substrates (carbohydrates) [27, 28].

The changes in soluble carbohydrate content in grain, stems, and leaves affected by the flooding treatment at 7 days after heading are shown in Fig. 1. First, in grain, although starch synthesis started at approximately 7 days after heading and rapidly increased at approximately 8 days after heading in the control, starch synthesis was inhibited in all submergence treatments, and especially in the muddy water and over-heading submergence treatments. The content of soluble sugar in grains increased until 11 days after heading in the control and decreased after 11 days after heading. The soluble sugar content was temporarily decreased for the $24 \mathrm{~h}$ treatment in all submergence treatments, but no significant change was observed from the $24 \mathrm{~h}$ treatment to the $96 \mathrm{~h}$ treatment.

In stems, starch content decreased in all treatments, including the control, and decreased more rapidly in the submergence treatments compared to that of the control. However, soluble sugar content tended to increase somewhat in contrast to the decrease in starch content in the submergence treatments. For leaves, the starch content tended to decrease in the muddy water and over-heading submergence treatments after $48 \mathrm{~h}$, but there was no significant increase or decrease in other treatments. The soluble sugar content decreased in all treatments, and was more severe in the submergence treatments than the control. In grains, the starch content increased in the control at 7 days after heading, but the starch content decreased in the muddy water and over-heading submergence treatment plots after $24 \mathrm{~h}$ and the starch content decreased in the muddy water and leaf exposure and clear water and over-heading submergence treatment plots after $48 \mathrm{~h}$. The decrease of starch content in grain tended to be somewhat larger at 14 days after heading than that of 7 days after heading (Fig. 2). These results were thought to occur because the amount of carbohydrate stored in stems and leaf sheaths before heading was mostly exhausted by 14 days after heading, and eventually the movement of stored carbohydrates from stems and leaf sheaths to grain was slightly smaller than that of 7 days after heading. The response in leaves was similar to that of 7 days after heading.

The changes in the partitioning ratio for organs (grain, stem, leaf) was affected by flooding treatment during the ripening stage as shown in Fig. 3. Although the distribution of assimilation products to grain increased, and decreased to stems and leaves, according to the ripening progress in the control, in the submergence treatment plots the distribution of assimilation products to stems increased, resulting in an inhibited supply of assimilation products to grain.

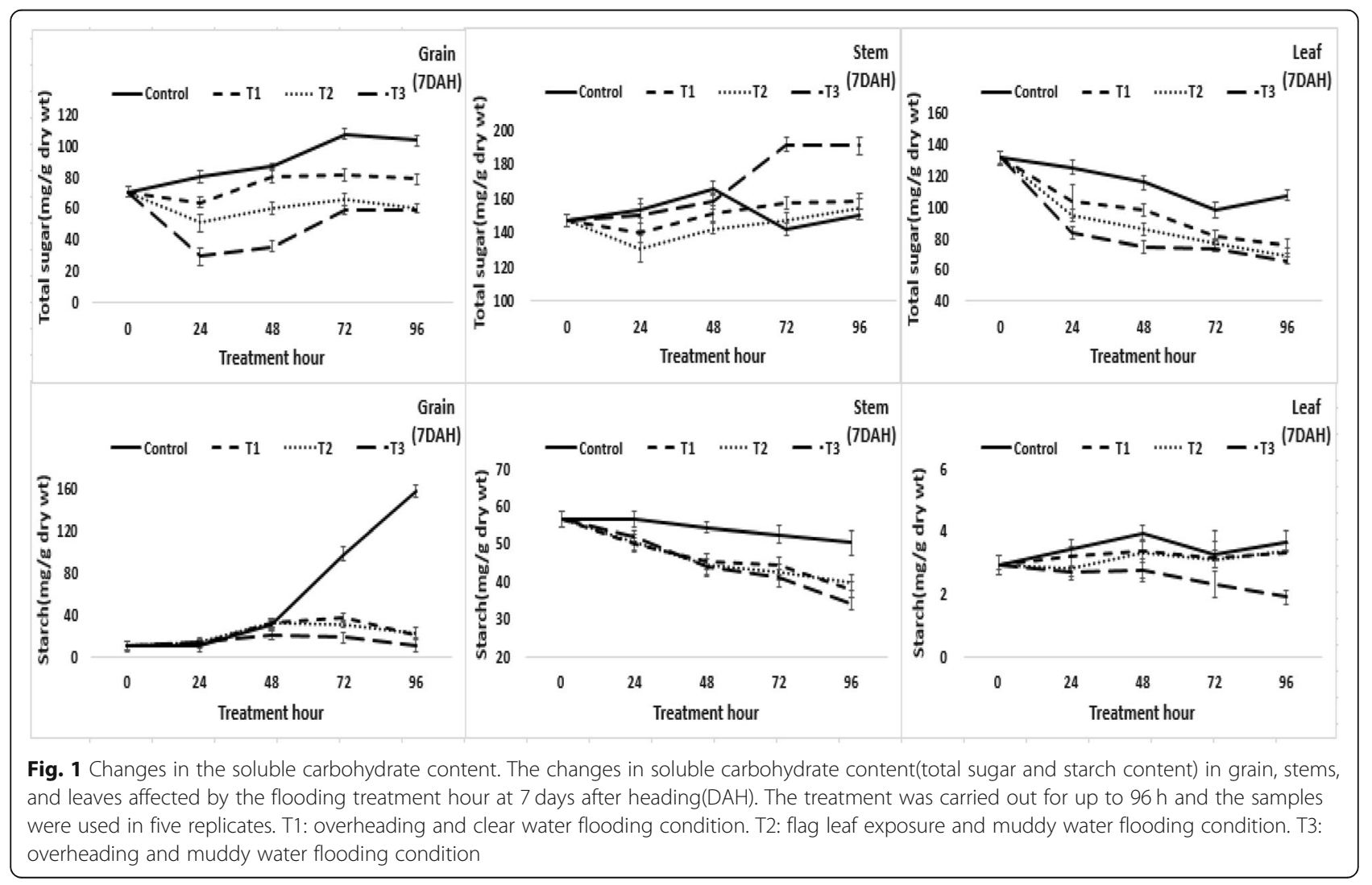



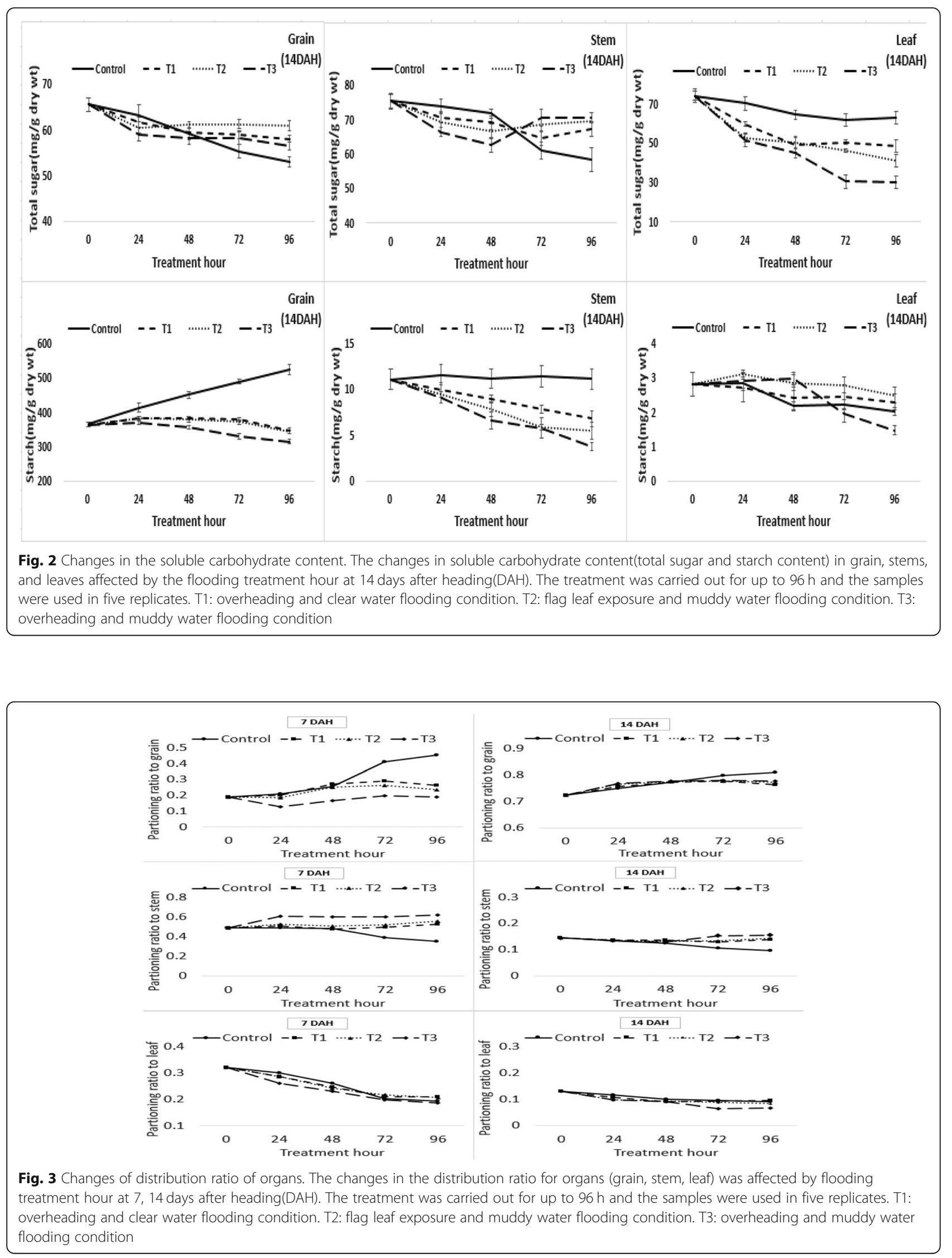
Differences in the relative expression of genes associated with sucrose and starch synthesis metabolism

The assimilation products synthesized by photosynthesis are converted into sucrose and are transported to the grain during ripening stage. The sucrose transported to the grain is converted to ADP-glucose, which is the final substrate for starch synthesis, via UDP-glucose, glucose-1-phosphate, and glucose-6-phosphate, and ADP-glucose is used in starch synthesis $[29,30]$. The relative expression of the genes involved in sucrose metabolism, which was affected by submergence in the ripening stage, is shown in Fig. 4. The expression of sucrose synthase (OsSusy), which converts sucrose to UDP-glucose and fructose [31,32], increased in grains and leaves, but not in stems. The expression of sucrose phosphate synthase (OsSPS), which converts UDP-glucose to sucrose [33,34], tended to decrease in grains and leaves, but not in stems. In addition, the expression level of the sucrose transporter (OsSUT), which regulates sucrose transport [35], decreased in the grains and leaves, but increased somewhat in the stems. In summary, the expression of OsSPS associated with sucrose accumulation [36] decreased in grains and leaves, but OsSUT expression increased in the stems. These expression characteristics of the sucrose-related genes were consistent with the results in Fig. 3, where the assimilation products were concentrated in the stems and not in the grains and leaves.
ADP-glucose, which is the final substrate for starch synthesis, is converted from glucose-1-phosphate by the action of ADP-glucose pyrophosphorylase [37, 38]. Then, ADP-glucose is synthesized as amylopectin and amylose by soluble starch synthase and granule-bound starch synthase (OsGBSS) to form starch [39, 40]. In addition, amylopectin is regulated in the structure and chain length by the influence of the starch branching enzyme (OsSBE) and debranching enzyme (OsPUL) in addition to starch synthase [41]. The relative expression of the genes involved in starch synthesis, which is affected by submergence in the ripening stage, is shown in Fig. 5. The expression level of sucrose synthase I (OsSS I) tended to increase somewhat in submergence treatments, but the expression levels of ADP-glucose pyrophosphorylase large unit (OsAGPL), ADP-glucose pyrophosphorylase small unit (OsAGPS), OsSBE, OsPUL, and OsGBSS tended to decrease. In particular, the expression levels of OsPUL, which regulate the structure of amylopectin and length of the glycosidic bond chain, was significantly increased in submergence treatments at 14 days after heading compared to that of 7 days after heading.

\section{Sequencing and selection of differentially expressed genes}

The results of the clean reads, which were obtained from the rice grain, stem, and leaf organs by trimming the short reads that were sequenced with the Illumina Hiseq

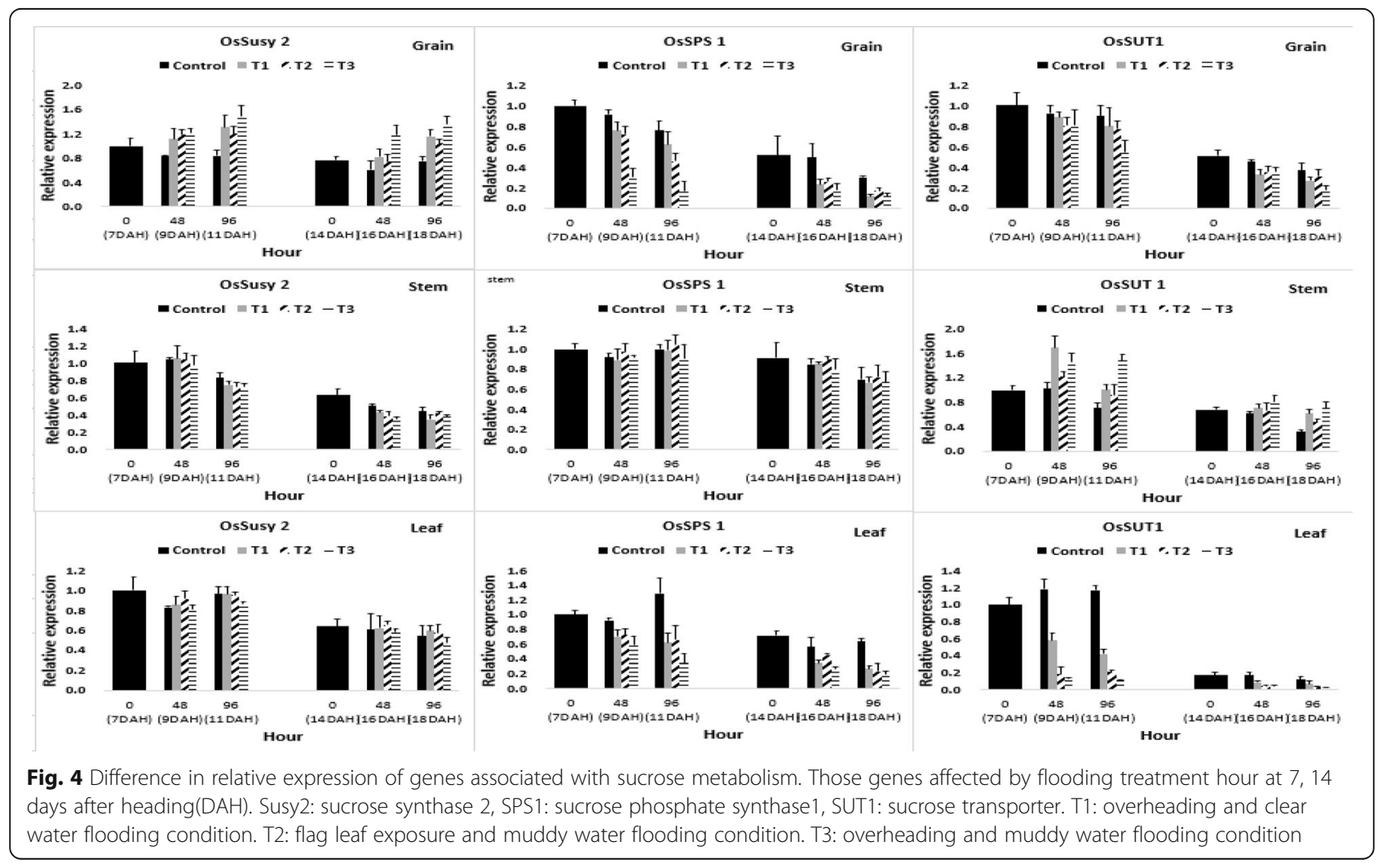




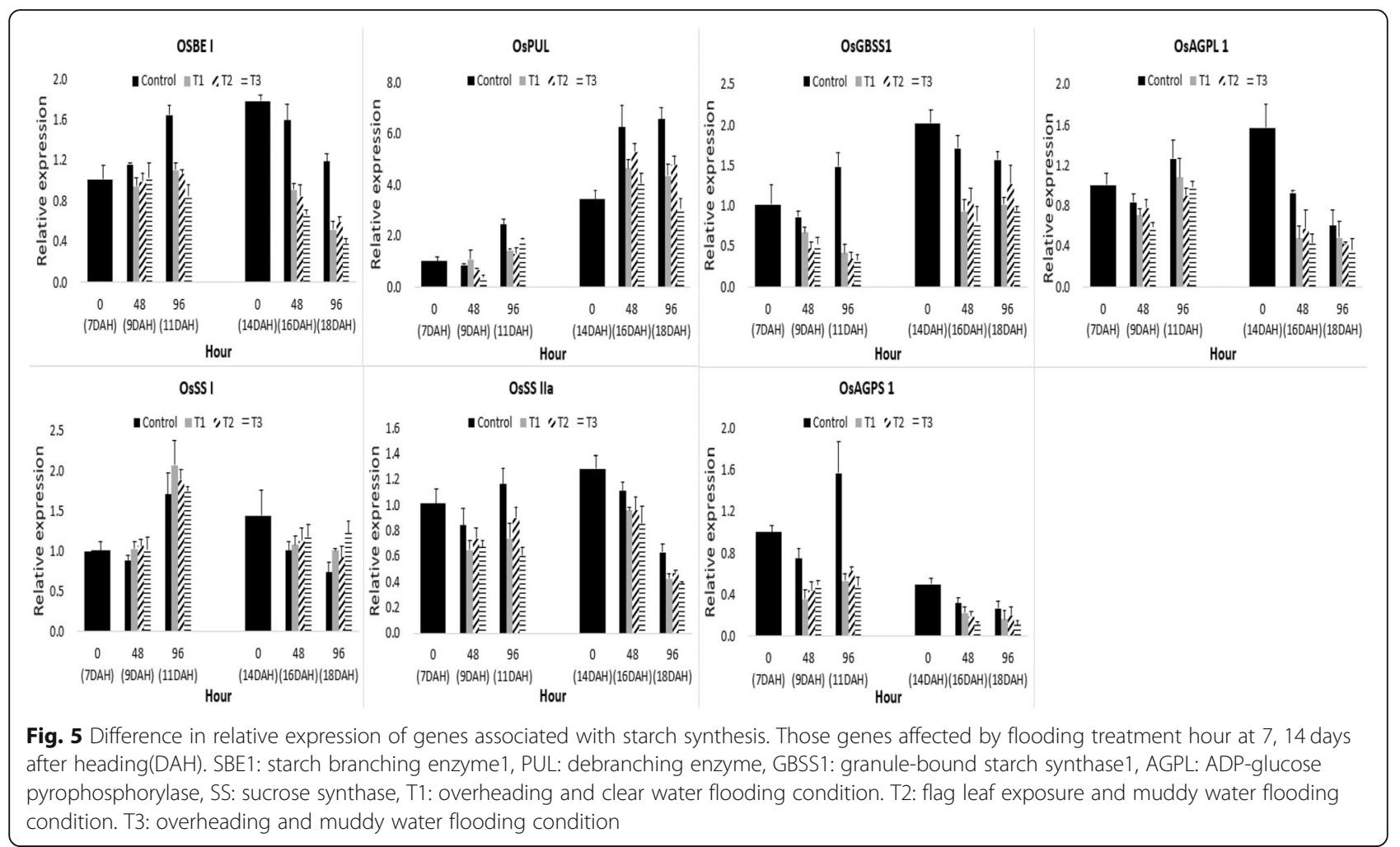

platform, are shown in Table 1. The total number of reads ranged from at least $11,032,891$ to a maximum of $17,673,004$. The total length of the reads ranged from at least $945,089,151$ to a maximum of $1,606,463,841$, and the average length of the reads ranged from a minimum of 85.40 to a maximum of 90.90 . The mapping results using these clean reads are shown in Table 2. Because the total number of reads between samples varied by 1.1 to 1.17 times, reads were randomly extracted to minimize errors during read counts and normalization, and the total number of reads was $11,032,891$ based on the smallest number of seed control treatments. The mapping rate was 83 to $87 \%$, with an average of $84.98 \%$.

The results of selecting the differentially expressed genes (DEGs) according to submergence effects on the grain, stem, and leaf organs are shown in Additional file 1: Figure S1. As shown in the figure, the number of up-regulated DEGs was 1459 in grain, 583 in stems, and 1211 in leaves. The highest number of up-regulated DEGs was found in grain, being 1459. The number of down-regulated DEGs was 517 in grain, 395 in stems, and 1223 in leaves. The highest number of up-regulated DEGs was found in the leaves, being 1223 . The information on the gene id, fold change value for selected DEGs, gene ontology (GO), and KEGG analysis results are shown in Additional file 2: Table S3. The MA-plots of differentially expressed genes (DEGs) between the control and submergence treatment for each tissue are shown in Additional file 3: Figure S2. In addition, the results obtained by summarizing the overlapping parts

Table 1 Trimmed sequencing data

\begin{tabular}{lllll}
\hline Sample description & & Num. of clean reads & Avg. length & Total length (bp) \\
\hline Seed & Control & $11,032,891$ & $85.7 \pm 2.2$ & $945,089,151 \pm 24,735,160$ \\
& Submergence & $12,595,149$ & $85.4 \pm 3.0$ & $1,075,509,880 \pm 38,212,576$ \\
Stem & Control & $12,765,878$ & $87.7 \pm 3.3$ & $1,119,579,740 \pm 42,307,259$ \\
& Submergence & $12,654,727$ & $88.0 \pm 1.7$ & $1,113,925,917 \pm 22,110,523$ \\
Leaf & Control & $16,376,497$ & $90.8 \pm 2.8$ & $1,486,987,894 \pm 46,242,526$ \\
& Submergence & $17,673,004$ & $90.9 \pm 2.8$ & $1,606,463,841 \pm 49,099,815$ \\
\hline
\end{tabular}

The results of the clean reads, which were obtained from the rice grain, stem, and leaf organs by trimming the short reads that were sequenced with the Illumina Hiseq platform. RNA was extracted from the samples (seed, stem, and leaf), which were treated with muddy water-irrigation for 4 days on the 14 th day after heading, and sequencing was performed on the extracted RNA, which was the same RNA sample used for real-time PCR with three replicates 
Table 2 Statistics of read mapping to reference gene set

\begin{tabular}{|c|c|c|c|c|c|c|c|c|c|c|}
\hline \multicolumn{2}{|c|}{ Sample description } & \multirow{2}{*}{$\begin{array}{l}\text { Total cleaned } \\
\text { reads (ea) }\end{array}$} & \multicolumn{2}{|l|}{ Aligned 0 times } & \multicolumn{2}{|c|}{ Aligned exactly 1 time } & \multicolumn{2}{|l|}{ Aligned $\geq 1$ times } & \multicolumn{2}{|c|}{ Mapping rate } \\
\hline & & & Reads (ea) & $\%$ & Reads (ea) & $\%$ & Reads (ea) & $\%$ & Reads (ea) & $\%$ \\
\hline \multirow[t]{2}{*}{ Seed } & control & $11,032,891$ & $1,399,412 \pm 8197$ & 13 & $4,775,660 \pm 1047$ & 43 & $4,857,820 \pm 7150$ & 44 & $9,633,480$ & 87 \\
\hline & submergence & $11,032,891$ & $1,622,211 \pm 2966$ & 15 & $4,797,957 \pm 1901$ & 43 & $4,612,724 \pm 4867$ & 42 & $9,410,680$ & 85 \\
\hline \multirow[t]{2}{*}{ Stem } & control & $11,032,891$ & $1,738,721 \pm 780$ & 16 & $4,665,276 \pm 1318$ & 42 & $4,628,895 \pm 2098$ & 42 & $9,294,171$ & 84 \\
\hline & submergence & $11,032,891$ & $1,917,617 \pm 6293$ & 17 & $4,463,265 \pm 1225$ & 40 & $4,652,010 \pm 5068$ & 42 & $9,115,274$ & 83 \\
\hline \multirow[t]{2}{*}{ Leaf } & control & $11,032,891$ & $1,471,592 \pm 6163$ & 13 & $4,785,651 \pm 3852$ & 43 & $4,775,648 \pm 2311$ & 43 & $9,561,299$ & 87 \\
\hline & submergence & $11,032,891$ & $1,790,521 \pm 6763$ & 16 & $4,385,443 \pm 9853$ & 40 & $4,852,428 \pm 3275$ & 44 & $9,242,371$ & 84 \\
\hline
\end{tabular}

Because the total number of reads between samples varied by 1.1 to 1.17 times, reads were randomly extracted to minimize errors during read counts and normalization, and the total number of reads was $11,032,891$ based on the smallest number of seed control treatments. The mapping rate was 83 to $87 \%$, with an average of $84.98 \%$

of each organ (grain, stem, and leaf) using selected useful genes (DEGs) is shown in Fig. 6. The number of DEGs that were up-regulated and did not overlap with each organ were the most abundant in grain, being 1154, and least in the stem, being 208 genes. In addition, among the up-regulated genes, the number of overlapping genes was the highest at 196 in the stems and leaves, the least, at 73, in the grain and stems. Conversely, the number of DEGs that were down-regulated and did not overlap with each organ were the most abundant in leaves with 912, and least in the stem, with 104 genes. Furthermore, the number of the DEGs that were up-regulated and overlapped with that of another organ was the most abundant between the stem and leaf with 196, and least between the grain and stem, with 73 genes. Conversely, the number of DEGs that were down-regulated and overlapped with that of another organ were the most abundant between the stem and leaf with 251, and least between the grain and stems, with 10 genes. Information on the genes represented by the Venn-diagram is shown in Additional file 4: Table S4.
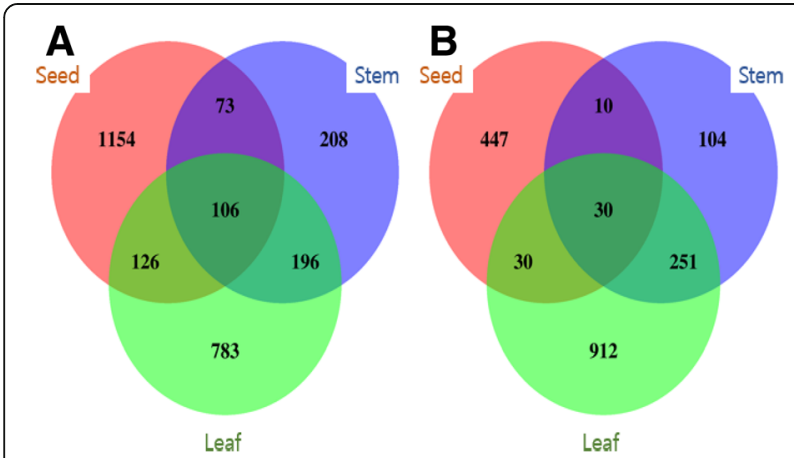

Fig. 6 Venn-diagram of differentially expressed genes. The number of genes obtained by summarizing the overlapping parts of each organ (grain, stem, and leaf) using selected useful genes (DEGs) affected by flooding treatment at 14 days after heading. a: Up-regulated, b: Down-regulated

\section{Gene ontology (GO) analysis}

To understand the functions of all these DEGs, we mapped them to terms in the GO database, searching for significantly enriched GO terms compared to the reference gene background (Fig. 7, Additional file 5: Figure S3).

In grain, firstly, according to biological processes, a high proportion of up-regulated DEGs mapped to "biological process" and "cellular process", and a high proportion of the down-regulated DEGs mapped to "transport" and "carbohydrate metabolic process" under the submergence treatments. Secondly, according to cellular components, a high proportion of the up- and down-regulated DEGs mapped to "cytoplasm" and "intracellular membranebounded organelle" under the submergence treatments. Finally, according to molecular functions, a high proportion of up-regulated DEGs mapped to "nucleic acid binding" and "nucleotide binding" and that of down-regulated DEGs mapped to "cation binding" and "nucleic acid binding" under the submergence treatments.

In the stem, firstly, according to biological processes, a high proportion of the up-regulated DEGs mapped to "transport," "multicellular organismal development," and "carbohydrate metabolic process" and a high proportion of the down-regulated DEGs mapped to "transport" and "phosphorus metabolic process" under the submergence treatments. Secondly, according to cellular components, a high proportion of the up-regulated DEGs mapped to "cytoplasm" and "thylakoid" and a high proportion of the down-regulated DEGs mapped to "cytoplasm" and "intracellular membrane-bounded organelle" under the submergence treatments. Finally, according to molecular function, a high proportion of the up-regulated DEGs mapped to "nucleic acid binding" and "nucleotide binding" and a high proportion of the down-regulated DEGs mapped to "nucleotide binding" and "peptidase activity" under the submergence treatments.

In the leaf, firstly, according to biological processes, a high proportion of the up-regulated DEGs mapped to "transport," "cell communication," and "response to hormone" and a high proportion of the down-regulated DEGs 


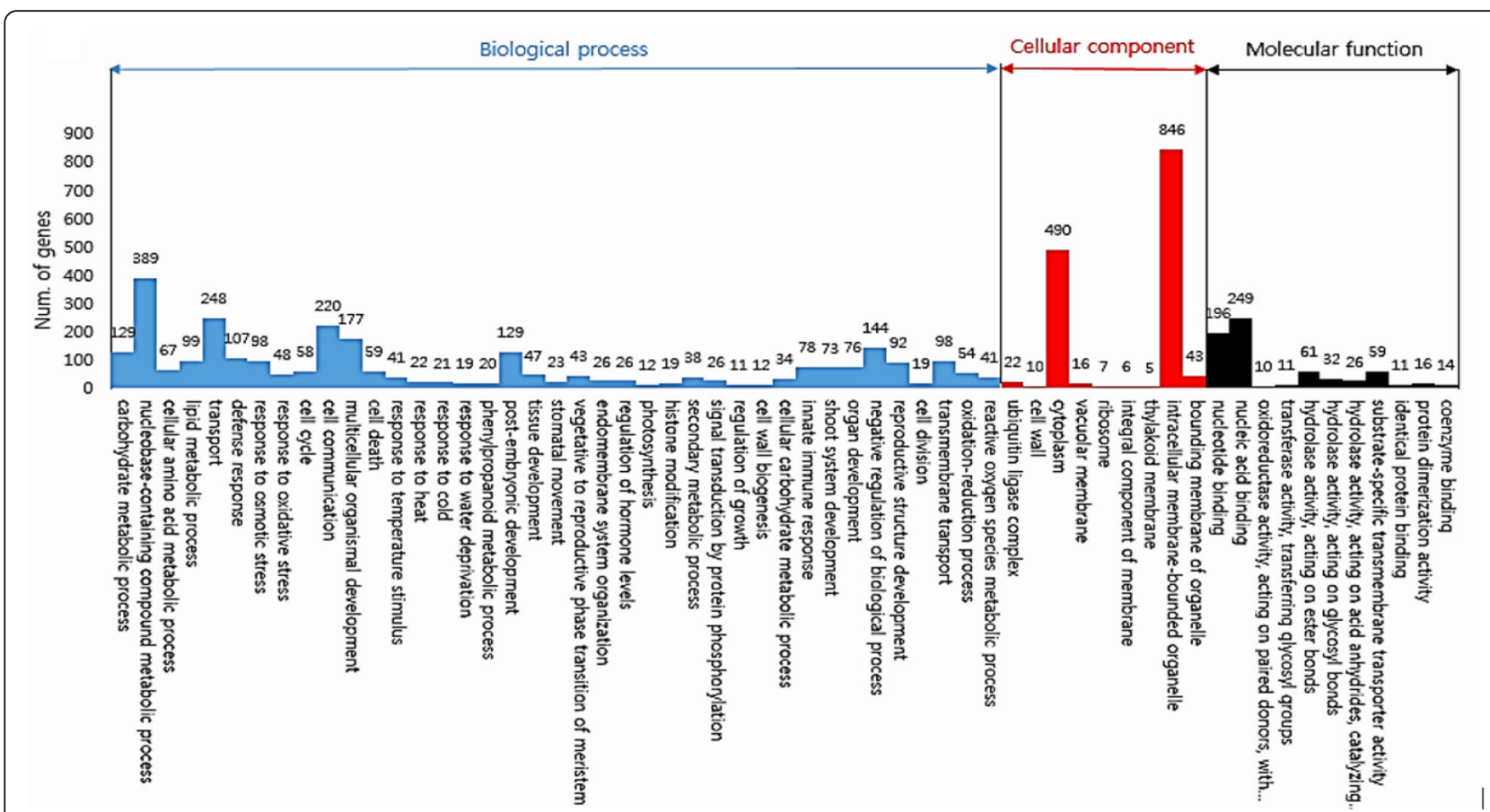

Fig. 7 Gene ontology enrichment analyses of datasets obtained by RNA-Seq. up-regulated genes in seed. According to biological processes, a high proportion of up-regulated DEGs mapped to "biological process" and "cellular process". According to cellular components, a high proportion of the up-regulated DEGs mapped to "cytoplasm" and "intracellular membrane-bounded organelle". According to molecular functions, the a high proportion of up-regulated DEGs mapped to "nucleic acid binding" and "nucleotide binding" under the submergence treatments

mapped to "transport" and "phosphorus metabolic process" under the submergence treatments. Secondly, according to cellular components, a high proportion of the up- and down-regulated DEGs mapped to "cytoplasm" and "intracellular membrane-bounded organelle" under the submergence treatments. Finally, according to molecular function, a high proportion of the up-regulated DEGs mapped to "transferase activity" and "signaling receptor activity" and a high proportion of the down-regulated DEGs mapped to "cation binding" and "nucleotide binding" under the submergence treatments.

In summary, according to biological processes, the DEGs that mapped to "transport" and "carbohydrate metabolic process" constituted a high proportion, and according to cellular components, the DEGs that mapped to "cytoplasm" and "intracellular membranebounded organelle" constituted a high proportion, and according to molecular function, the DEGs that mapped to "cation binding" and "nucleic acid binding" constituted a high proportion in all organs under the submergence treatments.

\section{Clustering analysis}

The results of hierarchical clustering analysis of DEGs affected by flooding treatment during the ripening stage are shown in Fig. 8. The DEGs with the same expression pattern were grouped into eight clusters from $\mathrm{C} 1$ to $\mathrm{C} 8$, and the DEG information and the results of Gene Ontology (GO) and KEGG analysis for each cluster group are shown in Additional file 6: Table S5). Most biological processes, such as carbohydrate metabolic process, transport, response to oxidative stress, photosynthesis, and response to hypoxia were distributed from cluster 1 to cluster 8 and showed a uniform distribution pattern; however, in the case of phosphorus metabolic processes (GO: 0006793) related to nucleic acid, carbohydrates, and ATP metabolism, 216 DEGs were distributed only in cluster 2, which exhibited a down-regulation pattern of DEGs in all organs including grain, stems, and leaves, and these DEGs were mostly associated with carbohydrate metabolism. In addition, in the case of the responses to hormones (GO: 0009725), 239 DEGs were distributed only in cluster 1 , which exhibited an up-regulation pattern of DEGs in all organs including grain, stems, and leaves, and these DEGs were mostly associated with hormones, such as auxin, gibberellin, and ethylene related to the avoidance strategy of submergence.

\section{Carbon fixation, photosynthetic electron transport,} glycolysis, starch, and sucrose metabolism (KEGG pathway) In the submergence condition, provision of oxygen becomes limited and anaerobic respiration occurs. 


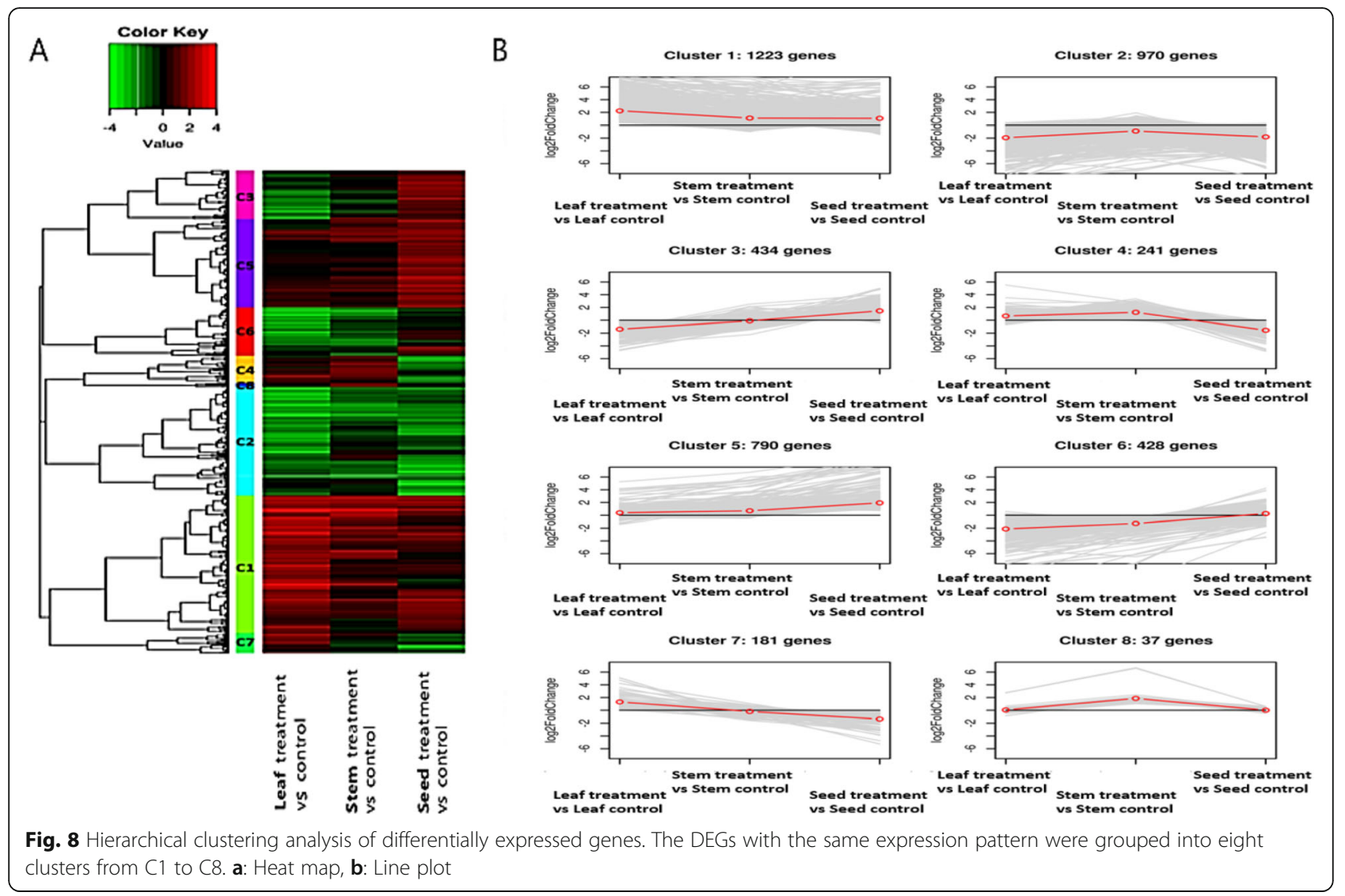

Consequently, photosynthesis and assimilation production are expected to decrease because of light shading. The metabolism of each previously selected DEG was analyzed using the KEGG mapper to examine responses in metabolism, including photosynthesis, respiration, assimilation production, and starch synthesis in the submergence condition. Additional file 7: Figure S4 shows the results of the photosynthetic carbon fixation pathway analysis using the KEGG mapper based on submergence treatments. In the metabolism of the Calvin-Benson cycle, the genes that encode trans-ketolase (this enzyme converts D-fructose 6-phoshpate to erythrose-4-phosphate, and glyceraldehyde-3phosphate to riblose-5phosphate) and ribulose-phosphate 3-epimerase (this enzyme converts xylulose5-phosphate to rublose-5phosphate) based on the submergence treatment did not show any difference before and after the treatment. Only DEGs that encoded glyceraldehyde 3-phosphate dehydrogenase (GAPDH), which converts 1,3-bisphospho glycerate to glyceraldehyde-3phoshate, were up-regulated, and all the other DEGs associated with the Calvin Benson cycle were down-regulated (Additional file 8: Table S6). These results were similar to the findings of Yang et al. (1993) [42] where the expression of genes that encode GAPDH increased during environmental stress conditions, including heat shock, anaerobiosis, and increased sucrose supply treatments.

Additional file 9: Figure S5 demonstrates the analysis of the resulting photosynthetic electron transport pathway based on the flooding treatment. In the photosynthetic KEGG pathway, the majority was down-regulated out of the total of 55 processes of photosynthesis-associated metabolism annotated to the reference japonica. Among the metabolism processes that included DEGs that showed a difference of at least two-fold according to the irrigation condition, only seven demonstrated a reaction. Among the seven metabolism processes, photosystem II oxygenevolving enhancer protein 3 (Psb Q) in was the only one that was up-regulated. Photosystem II $10 \mathrm{kDa}$ protein (Psb R), photosystem II $22 \mathrm{kDa}$ protein (Psb S), Cytochrome b6/ f complex iron-sulfur subunit (Pet $\mathrm{C}$ ), ferredoxin--NADP+ reductase (pet $\mathrm{H})$, and $\mathrm{F}$-type $\mathrm{H}+$-transporting ATPase subunit (gamma a, b) were down-regulated. Photosynthetic electron transport pathway-associated DEGs according to the submergence treatment were identified, including LOC_Os07g37030, LOC_Os08g10020, and LOC_ Os04g55960 (Additional file 10: Table S7).

The results of the metabolism pathway analysis according to the submergence treatments are shown in Additional file 11: Figure S6. Genes that encoded 
phosphoglucomutase, which converts $\alpha$-D-glucose-1P to $\alpha$-D-glucose-6P, were down-regulated in leaves, but the expression showed no difference in stems and grain. The processes in which $\alpha$-D-glucose-6P was converted to phosphoenolpyruvate through glyceraldehyde-3P and glycerate-3P were all up-regulated both in stems and grain. The processes did not show any regular tendency in leaves, such as up- or down-regulation. The genes that encode pyruvate decarboxylase (4.1.1.1) and alcohol dehydrogenase (1.1.1.1) (which are associated with pyruvate's ethanol formation through acetaldehyde) were up-regulated in all three organs: grain, stems, and leaves (Additional file 12: Table S8).

Figure 9 and Additional file 13: Figure S7 shows changes in sucrose and starch metabolism in the submergence conditions. Principal changes were observed in the process of synthesis from sucrose to starch, and those synthesizing beta-glucosidase and trehalose activity increased according to environmental stress. First, in the synthesis process of sucrose to starch in grain, the conversion of sucrose to $\mathrm{D}$-fructose and to $\mathrm{D}$-glucose (3.2.1.26) was down-regulated in all organs. Later, in the process of conversion to ADP-glucose, the synthesis substrate was $\alpha$-D-glucose-1P through $\mathrm{D}$-fructose-6P and $\mathrm{D}$-glucose-6P was up-regulated in grain and stem, but no reaction was observed in leaves. Conversely, the process of sucrose conversion to UDP-glucose was up-regulated in grain, stems, and leaves, whereas
ADP-glucose pyrophosphorylase, starch synthase, and starch branching enzyme were down-regulated in grain and leaves from the ADP-glucose synthesis (2.7.7.27) to starch synthesis $(2.4 .1 .21,2.4 .1 .18)$. In stems, only ADP-glucose pyrophosphorylase was up-regulated. In starch and sucrose metabolism, beta-glucosidase is associated with producing $\mathrm{D}$-glucose in 1,3- $\beta$ glucan, $\beta$-D-glucose, and cellulose (3.2.1.39, 3.2.1.21, 3.2.1.4). This beta-glucosidase has various functions, including producing defense-associated bioactive compounds during environmental stress, degradation of endosperm cell walls during germination, activation of phytohormones, and lignification, which produces lignin in cell walls and mesoderm [43]. The expression of genes encoding these functions was down-regulated in grain and leaves, and up-regulated in stems and associated DEGs (Additional file 14: Table S9) LOC-Os11g45710 (beta-glucosidase-like SFR2, chloroplastic), and LOC_Os0 1g71860 (glycosyl hydrolases family 17) were observed. Beta-glucosidase is also reported as a substance associated with the expression of genes induced by environmental stress, such as drought and salt [44]. Synthesis of trehalose, which is known to control starch synthesis by activating ADP-glucose pyrophosphorylase (AGPase), is controlled by trehalose 6-phosphate synthase (2.4.1.15), which produces trehalose-6phosphate in UDP-glucose, and by trehalose 6-phosphate phosphatase (3.1.3.12), which produces trehalose in trehalose-6phosphate.

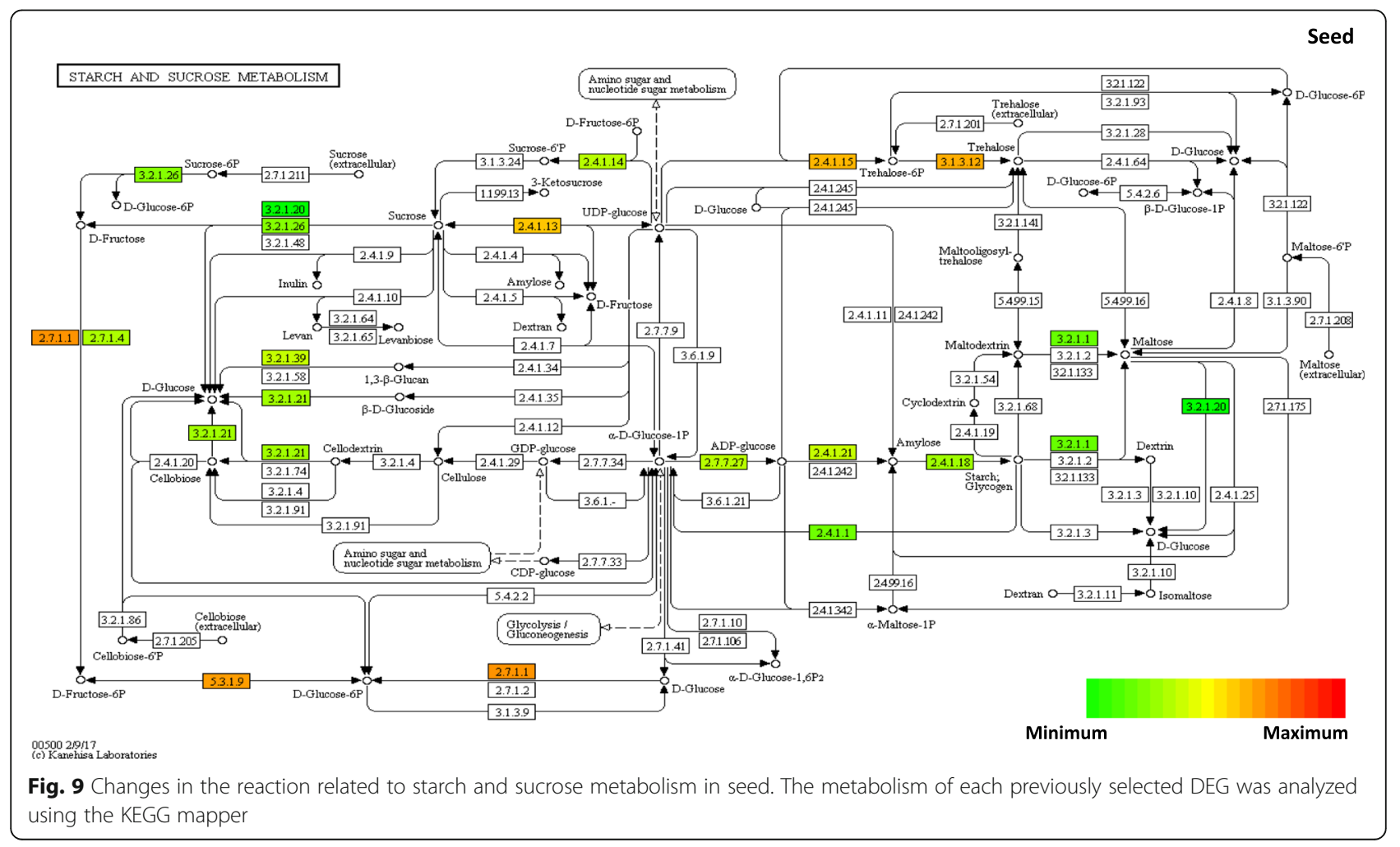


Similar to the experiment by Koble et al. (2005) [45] in which AGPase activity increased because of the increased expression of trehalose 6-phosphate phosphatase (TPP) gene, the expression of TPP and AGPase in leaves was down-regulated. Conversely, in grain the expression of AGPase was down-regulated despite the up-regulation of TPP expression, being different than that of leaves. The information of DEGs associated with different amounts of expression in each pathway is demonstrated in Additional files 8, 10, 12 and 14: Tables S6, S7, S8, and S9.

\section{Discussion}

In rainfed lowlands vulnerable to flood in Southeast Asia, and West Africa, precipitation occurs in meter units, and a long-term precipitation occurs at times lasting for more than a month [46]. The International Rice Research Institute (IRRI) conducted numerous studies of SUB1A gene [47], which controls the survival properties during long-term flood stress by controlling the consumption of carbohydrate storage in anaerobic conditions, with the goal of developing flood-resistant rice that survives long-term raining periods. The institute developed a new rice variety by introducing SUB1A gene to rice, which does not contain the SUB1A gene. A back cross study was conducted to recover several traits, including head-rice ratio, and protein and amylose content [48, 49].

Recently, research has attempted to develop a breeding program for new flood-resistant varieties. Studies were conducted to identify a variety of genes and other QTLs that could have new effects in combination with the flood-resistant traits of SUB1, in addition to those of the QTL already associated with SUB1 that controls flood-resistant traits. However, little has been found in physiological and molecular biological terms $[20,50]$. In Sharma's study [21], to provide insights in to novel aspects of SUB1A-mediated tolerance, some intermediate tolerance varieties, such as IR64, carry the allelic variant SUB1A-2 and its derived tolerant near the isogenic line IR64-Sub1, which carries the SUB1A-1 allele were used to compared the expression of nearly 2500 rice TF genes. This identified distinct sets of transcription factor genes affected by submergence. Additionally, in Xiang's study [22], to provide new insight into the mechanism of phytohormone-regulated submergence response in rice, paclobutrazol, which could significantly enhance rice seedling survival in submergence conditions, by retaining a higher level of chlorophyll content and alcohol dehydrogenase activity and decelerating the consumption of non-structure carbohydrate, was treated with rice. In total, 3936 differentially expressed genes (DEGs) that could enhance the submergence tolerance were identified by transcriptomic analysis. Among those DEGs, they selected CIPK15, MPK3, SD-1, and OScyt-inv1 as the key genes that are expected to play important roles in enhancing submergence tolerance. Moreover, in Hsu's study [23], they conducted RNA-seq analysis in order to identify transcriptome characteristics for the difference in early growth between submergence tolerant and sensitive varieties during the germination stage under submergence conditions. A comparative analysis of biological metabolic pathways, including hormone synthesis, cell wall growth, glycolysis for six genotypes were conducted. In addition, candidate DEGs such as OsTPP7, HXK7, and PGM, which could affect early growth under submergence conditions, were selected. Similar to these studies, transcriptome analysis studies related to submergence stress have been conducted recently.

Reduced head-rice ratio and ripening rate following flood damage during the ripening period are likely caused by an excessive consumption of respiratory substrate caused by reduced photosynthesis and anaerobic respiration, and limited assimilation product supply to grain because of an increased stem distribution. In the submergence treatment plots the distribution of assimilation products to the stems increased, resulting in an inhibited supply of assimilation products to grain (Fig. 3). The supply of these assimilation products to the stems appears to occur for stem elongation, according to the avoidance strategy. These results are similar to those of Das [7], in which there was an increased carbohydrate content in the stems for elongation in the submergence treatment. This phenomenon was verified by the fact that the expression of sucrose phosphate synthase (SPS) associated in sink activity, which induced sucrose accumulation in tissues, was reduced in grain and leaves compared to that of the control, whereas the expression was maintained in stems. It was also demonstrated through the reduction of sucrose transporter (SUT) associated with sucrose transport in grain and leaves, whereas it increased in stems (Fig. 4). These results are similar to those of Adak [51] in that sucrose phosphate synthase activity decreased in submergence treatment in rice.

The limited supply of assimilation products to grain affected the starch synthesis metabolism. There was no difference in expression during the conversion from UDP-glucose synthesized from sucrose to $\alpha$-D-glucose-1P. The conversion of $\alpha$-D-glucose-1P to the final substrate of starch synthesis ADP-glucose, and the synthesis of starch synthase (SS) and starch branching enzyme (SBE) to amylose and amylopectin were all down-regulated (Fig. 9, Additional file 13: Figure S7). This was probably because part of UDP-glucose, which should be used for conversion to the ADP-glucose synthesis substrate $\alpha$-D-glucose-1P, was synthesized to trehalose-6P and then to trehalose, as shown in the resulting increased expression of genes that encode trehalsoe-6P-sytnahse and trehalose 6-phosphate phosphatase (Fig. 9, Additional file 13: Figure S7). In Locke's study [52], the involvement of low energy sensing 
during submergence was supported by dynamics in trehalose-6-phosphate and mRNAs encoding key enzymes, which were modulated by SUB1A. The role of trehalose synthesis in a condition with limited transport of assimilation product to grain should be investigated further. Meanwhile, the expression levels of OsPUL, which regulate the structure of amylopectin and length of the glycosidic bond chain, was significantly increased in submergence treatments at 14 days after heading compared to that at 7 days after heading(Fig. 5). These results suggest that the decrease in the expression of OsPUL in submergence treatments may have affected the results showing an significant increase in chalky grain [53] at 14 days after heading compared to that of 7 days after heading [54].

Pyruvate produced through the mean process was converted to acetyl-CoA in general aerobic respiration conditions, and produced energy, such as ATP through the TCA cycle. However, respiration becomes inefficient producing a much smaller amount of energy in anaerobic respiration because of the submergence compared to aerobic respiration. Alcohol fermentation or lactic acid fermentation generating ethanol, and lactate occurs in anaerobic respiration. The glycolysis/gluconeogenesis pathway affected by submergence treatment (Additional file 11: Figure S6) was analyzed. The conversion of glucose to pyruvic acid in the submergence treatments was up-regulated throughout the entire process in grain and stems. The amount of expression was greater in grain than stems. Conversely, both up- and down-regulations were observed, but no regular tendency was observed in the entire process in leaves. With respect to the alcoholic fermentation of anaerobic respiration in pyruvate that produces ethanol, the expression of DEGs, such as alcohol-dehydrogenase (LOC_Os11g10480, LOC_Os11g1 0510), aldehyde-dehydrogenase (LOC_Os02g49720), and pyruvate decarboxylase (LOC_11g38910) tended to all be up-regulated in grain, stems, and leaves. The difference in alcohol fermentation-associated DEG expression was substantially greater in grain (Additional file 12: Table S8). Phosphoenolpyruvate carboxykinase (LOC_Os10g13700, LOC_Os03g15050) (PCK) converts oxaloacetate (OAA) produced through the TCA cycle back to phosphoenolpyruvate. It was down-regulated in grain following the submergence treatment, but tended to be up-regulated in stems and leaves. PCK is known to decarboxylate OAA in $\mathrm{C} 4$ or CAM plant photosynthesis to provide $\mathrm{CO}_{2}$, or to control gluconeogenesis during germination or ripening [55]. However, little is known about its role in rice, and the PCK reaction in submergence treatment should be investigated further.

As it is known that gas diffusion slows down 10,000 times or more in submergence conditions relative to the atmosphere, and reduces photosynthesis [4], only DEGs that encoded GAPDH that converts 1,3-bisphospho glycerate to glyceraldehyde-3phoshate in the Calvin Benson cycle were up-regulated. Genes associated with the rest of the process were down-regulated. A study reported that GAPDH expression increased in response to environmental stresses, such as high temperature, drought, and hypoxia, in addition to its well-known role in glycolysis and the Calvin Benson cycle [42]. Kappachery et al. (2015) [56] examined the response of GAPDH-overexpressed transgenic potatoes in drought stress conditions. They observed that the survival rate increased in the drought stress condition compared to that of the control. This was probably because GAPDH played the role of distributing the carbohydrate supply to the pathways, including glycolysis and the Calvin Benson cycle, supplying additionally energy in the limited energy supply conditions because of the environmental stress [57]. Further study is required to elucidate its response and role in rice submergence conditions.

This study analyzed the changes observed in metabolism associated with the production of assimilation products, transportation to grain, and starch synthesis, which affects the ripening of rice in submergence conditions. The results established a network of changing responses between important factors in submergence conditions other than the resistance mechanism of SUB1A, and SK1 and 2 genes that previously were intensively studied. They also suggest important information regarding DEGs, and can be used as basic data for developing varieties and technology adaptive to domestic flood damage conditions. This will ultimately contribute to the stable production of rice produced in frequently flooded areas.

\section{Conclusions}

The following are analysis results of the characteristics of assimilation product distribution and transcriptome according to rice ripening stages and damages in each flood condition.

1. In case of flood damage during the ripening period, the ratio of assimilation product distributed to stems is increased and that to grain decreased. The increased ratio of assimilation product distribution to stems is likely intended for extended aboveground growth according to the flood escape mechanism.

2. OsSPS is associated with sink activity, which induces the accumulation of sucrose in tissues. Regarding its distribution, it was observed in that the expression of OsSPS decreased in grain and leaves in submergence conditions compared to that of the control, and that of OsSUT associated with sucrose transport decreased in grain and leaves, whereas it increased in stems.

3. There was no difference in the expression of genes associated with the conversion of UDP-glucose produced from sucrose transported to grain to $\alpha-\mathrm{D}$ - 
glucose-1P. Conversely, those genes were downregulated that encoded SS and SBE associated with the conversion of $\alpha$-D-glucose-1P to the final starch synthesis substrate ADP-glucose, and with the synthesis of amylose and amylopectin.

4. DEGs were selected that demonstrated significant differences in expression in each of organ, grain, stems, and leaves, according to flooding treatment. Expression patterns of the selected genes were analyzed with clustering analysis. The cluster group was categorized into $\mathrm{C} 1$ through $\mathrm{C} 8$.

5. The selected DEG metabolism processes associated with photosynthesis, respiration, assimilation production, and starch synthesis were analyzed using the KEGG mapper. Glyceraldehyde 3phosphate dehydrogenase (GAPDH), trehalose 6phosphate phosphatase (TPP), and phosphoenolpyruvate carboxykinase (PCK) demonstrated specific responses in the metabolism processes. Based on this, several DEGs were selected for further study of their role in flood damage.

\section{Methods}

\section{Experiment materials and method}

Nampyeongbyeo (rice of japonica type) was used in this experiment. Nampyeonbyeo was obtained from the Nation institute of crop science in Korea. Three seedlings were transplanted in $1 / 5000$ a plots, and grown in natural weather conditions until the submergence treatment. Submergence treatment was conducted at the submergence treatment facilities based in the Artificial Weather Block of the National Institute of Crop Science. The average temperature of submergence treatment was $24^{\circ} \mathrm{C}$ (minimum $19^{\circ} \mathrm{C}$ and maximum $29^{\circ} \mathrm{C}$ ), and $\mathrm{pH}$ was set between 7 and 7.5. The treatment was divided into clear water and muddy water. The muddy water was conditioned using field dirt focusing on dissolved oxygen and shade level. Changes of the water condition by submergence treatment are shown in Additional file 15: Table S1. Dissolved oxygen was categorized into before flooding treatment $(8.0 \mathrm{mg} / \mathrm{L}) ; 24 \mathrm{~h}$ after the flooding treatment $(7.4 \mathrm{mg} / \mathrm{L}) ; 48 \mathrm{~h}$ after $(6.6 \mathrm{mg} / \mathrm{L}) ; 72 \mathrm{~h}$ after $(5.1 \mathrm{mg} / \mathrm{L})$; and $96 \mathrm{~h}$ after $(4.0 \mathrm{mg} / \mathrm{L})$. Muddy water was categorized into the before flooding treatment $(7.2 \mathrm{mg} / \mathrm{L}) ; 24 \mathrm{~h}$ after the flooding treatment $(6.1 \mathrm{mg} / \mathrm{L}) ; 48 \mathrm{~h}$ after $(4.5 \mathrm{mg} / \mathrm{L}) ; 72 \mathrm{~h}$ after $(2.7 \mathrm{mg} / \mathrm{L})$; and $96 \mathrm{~h}$ after $(2.1 \mathrm{mg} / \mathrm{L})$. To analyze the change of insolation by flooding treatment, the amount of insolation was measured at $11 \mathrm{am}$ in the morning for each treatment condition. The insolation of clear and muddy waters was measured at underwater flag leaf level. Flood treatment was performed 7 and 14days after heading according to each ripening stage in 59\% shade to natural light for clear water, and $94 \%$ shade for muddy water. The treated plots were named T1: Overheading and clear water, T2: Flag leaf exposure and muddy water, and T3: Overheading and muddy water flooding. Names were based on each flooding condition.

\section{Content of starch and free sugar}

Starch content was measured and analyzed using a starch assay kit (Sta20, Sigma, USA). A $25 \mathrm{mg}$ ground sample (grain, leaf, and stem) was treated with $5 \mathrm{~mL}$ of $80 \%$ ethanol to eliminate maltodextrin and glucose. Then, $1 \mathrm{~mL}$ DMSO was added to the sample, and it was heated in boiling water for $5 \mathrm{~min}$. Resistant starch was eliminated. Thermostable a-amylase and MOPS buffer were added to the sample, and it was kept in boiling water for $10 \mathrm{~min}$. Amyloglucosidase was then added. The sample was kept at $50^{\circ} \mathrm{C}$ for $30 \mathrm{~min}$ to decompose starch. Glucose content was measured at $540 \mathrm{~nm}$ wavelength by color reaction.

For free sugar analysis, $1 \mathrm{~g}$ of frozen sample (grain, flag leaf, stem) was treated with $20 \mathrm{~mL}$ of $50 \%$ acetonitrile solution at $30^{\circ} \mathrm{C}$, and stirred at $200 \mathrm{rpm}$ for $18 \mathrm{~h}$. The extracted sample was centrifuged at $4000 \mathrm{rpm}$ for 10 min. The supernatant was removed, and centrifuged at $13500 \mathrm{rpm}$ for $10 \mathrm{~min}$. It was then filtered at $0.2 \mu \mathrm{m}$ using a $1 \mathrm{~mL}$ syringe, and was injected to a UPLC vial. ACQUITY UPLC (Waters, USA) and ACQUITY UPLC BEH amide column $(2.1 \times 50 \mathrm{~mm}, 1.7 \mu \mathrm{m})$ were used for the analysis. Phase A was $80 \%$ ACN with $0.2 \%$ TEA, and Phase B 30\% ACN with 0.2\% TEA. Flow rate was 0.150 $\mathrm{mL} / \mathrm{min}$, and flow profile $93 \% / 7 \% \mathrm{~B}$.

\section{RNA extraction and gene expression}

For RNA extraction, each of the three samples (in the seed, stem, and leaf), which were treated with muddy water-irrigation for 4 days on the 14th day after heading, were taken from each ripening stage, and were immediately frozen using liquid nitrogen. The samples were stored at $-80^{\circ} \mathrm{C}$. Total RNA was extracted according to the Chang et al. (1993) protocol [58]. cDNA was synthesized using Primescript RT reagent kit with gDNA eraser (Takara bio Inc., Japan). In Realtime PCR, SYBRGreen (SYBR Realtime PCR Master Mix, Toyobo) was used for fluorescent dye. The analysis was conducted with three replicates per tissue using the Roter-Gene TM6000 (Corbett Research, Australia). The primer sequences are shown in Additional file 16: Table S2.

\section{Sequence pretreatment}

RNA was extracted from the samples (seed, stem, and leaf), which was treated with muddy water-irrigation for 4 days on the 14th day after heading, and sequencing was performed on the extracted RNA, which was the same RNA sample used for real-time PCR with three replicates. For pretreatment of the sequenced short 
reads, duplicated reads produced by the PCR during the library development were filtered through in-house scripts. Final trimmed data were refined using Dynamic trim and Length sort of the SolexaQA [59] package. Dynamic trim renders data as refined cleaned reads by trimming bad quality base on both ends of short reads according to the Phred score. Length sort eliminates reads with too much base cut off by Dynamic trim. Phred score was $>20$ in Dynamic trim, and short read length was $>25 \mathrm{bp}$ in Length sort.

\section{Read mapping, normalization, annotation}

Read mapping was conducted using Bowtie (v.2.1.0) software based on the Langmead and Salizberg (2012) [60] method (mismatch $\leq 2 \mathrm{bp}$, penalty). Expression was measured by the total number of reads mapped on each gene. The $\mathrm{R}$ package DEseq library [61] was implemented to calculate proper gene expression values for samples with data deviation. To examine the function of selected genes, the annotation information provided by Phytozome [62] DB was used.

\section{Selection of DEGs}

For selection of DEGs in each sample, both the 2-fold change method, which verifies a difference in expression greater than twice between expression values mapped in each gene in each sample, and the binomial test method in which the adjusted $P$-value (FDR) satisfying 0.01 or lower were simultaneously applied [63]. In this study, it was defined as up-regulation if log_2 (Fold Change) was greater than 1, and down-regulation if smaller than -1 . And this value can be found in Additional file 2: Table S3.

\section{Analysis of DEGs function and expression patterns}

Alignment was conducted using DEG candidates and sequences provided by GO DB for gene ontology analysis [64]. The total number of genes by function was set at counts $>1$ for thresholds. GO depths were set at 3 , and were categorized into three functional categories, BP (Biological Process), CC (Cellular Component), and MF (Molecular Function). Annotation (filter standard: e-value $\leq 1 \mathrm{e}-10$, best hits) was conducted with amino acid sequence and BLASTX provided on KEGG for KEGG analysis. Clustering analysis was performed to identify gene expression patterns using selected DEG information. Hierarchical clustering analysis was conducted using R amap [65] and gplots library.

\section{Additional files}

Additional file 1: Figure S1. The number of differentially expressed genes (DEGs) of organs. The results of selecting the DEGs according to $96 \mathrm{~h}$ submergence effects on the grain, stem, and leaf organs at 14 days after heading. (DOCX $253 \mathrm{~kb})$
Additional file 2: Table S3. The differentially expressed genes (DEGs) in seed, stem, and leaf response to submergence treatment for $94 \mathrm{~h}$ at 14 days after heading. (XLSX $1215 \mathrm{~kb}$ )

Additional file 3: Figure S2. MA-plots of differentially expressed genes (DEGs) between control and submergence treatment for each tissue. (DOCX $104 \mathrm{~kb}$ )

Additional file 4: Table S4. Venn-diagram of differentially expressed genes affected by flooding treatment during the ripening stage. (XLSX $513 \mathrm{~kb}$ )

Additional file 5: Figure S3. Gene ontology enrichment analyses of datasets obtained by RNA-Seq. (DOCX $495 \mathrm{~kb}$ )

Additional file 6: Table S5. The hierarchical clustering analysis data of the differentially expressed genes (DEGs) in seed, stem, and leaf responses to submergence treatment. (XLSX $722 \mathrm{~kb}$ )

Additional file 7: Figure S4. Changes in the reaction related to carbon fixation in photosynthetic organism metabolism in leaves. (DOCX $116 \mathrm{~kb}$ )

Additional file 8: Table S6. The KEGG pathway enrichment analysis of the differentially expressed genes (DEGs) related to carbon fixation in photosynthetic organism metabolism. (XLSX $30 \mathrm{~kb}$ )

Additional file 9: Figure S5. Changes in the reaction related to photosynthetic electron transport metabolism. (DOCX 206 kb)

Additional file 10: Table S7. The KEGG pathway enrichment analysis of the differentially expressed genes (DEGs) related to photosynthesis (electron transport and antenna proteins) metabolism. (XLSX 335 kb)

Additional file 11: Figure S6. Changes in the reaction related to glycolysis, gluconeogenesis metabolism in seed, stems, and leaves. (DOCX 312 kb)

Additional file 12: Table S8. The KEGG pathway enrichment analysis of the differentially expressed genes (DEGs) related to glycolysis/ gluconeogenesis metabolism. (XLSX $36 \mathrm{~kb}$ )

Additional file 13: Figure S7. Changes in the reaction related to starch and sucrose metabolism in stems and leaves. (DOCX $277 \mathrm{~kb}$ )

Additional file 14: Table S9. The KEGG pathway enrichment analysis of the differentially expressed genes (DEGs) related to starch and sucrose metabolism. (XLSX 39 kb)

Additional file 15: Table S1. Changes of water condition by submergence treatment during ripening period. (DOCX $16 \mathrm{~kb}$ )

Additional file 16: Table S2. Gene specific PCR primer sets for quantitative RT-PCR amplification. (DOCX $17 \mathrm{~kb}$ )

\section{Abbreviations}

DEG: Differentially expressed gene; GO: Gene ontology; Heat map: A graphical representation of data where the individual values contained in a matrix are represented as colors.; KEGG: Kyoto Encyclopedia of Genes and genomes; NSC: Nonstructural carbohydrate; PCR: Polymerase chain reaction; QTL: Quantitative trait locus; T1: Overheading and clear water flooding condition; T2: Flag leaf exposure and muddy water flooding condition; T3: Overheading and muddy water flooding condition; TCA

Cycle: Tricarboxylic acid cycle

\section{Acknowledgements}

We express our sincere gratitude to every person who cooperated with us for this research project.

\section{Funding}

The design of this research, the collection, analysis and interpretation of data was carried out as a Rural Development Administration (RDA) research project (Research Title: Study on physiology of rice according to high temperature, research registration number: PJ01195201) under the support of RDA.

Availability of data and materials

All data generated or analyzed during this study are included in this published article and its supplementary information files. 


\section{Authors' contributions}

HSL, KJC designed the experiments. HSL performed the treatments, sample collection and laboratory work. HSL analyzed and interpreted the RNA-Seq data. WHH, JHJ, SHA, JSB, HYJ, HKP, BIK, JTY, GHL assisted with data analysis and aided in writing the manuscript. All authors read and approved the final manuscript.

\section{Ethics approval and consent to participate} Not applicable.

\section{Consent for publication}

Not applicable.

\section{Competing interests}

The authors declare that they have no competing interests.

\section{Publisher's Note}

Springer Nature remains neutral with regard to jurisdictional claims in published maps and institutional affiliations.

Received: 13 December 2017 Accepted: 27 November 2018 Published online: 08 January 2019

\section{References}

1. FAOSTAT. Rice Market monitor (April, 2017) www.fao.org/fileadmin/ templates/est/COMM_MARKETS_MONITORING/Rice/Images/RMM/RMM_ APR17_H.pdf.

2. Kotak S, Larkindale J, Lee U, von Koskull-Dőrling P, Vierling E, Scharf K-D. Complexity of the heat stress response in plants. Curr Opin Plant Biol. 2007; 10:310-6.

3. Kim YK. A hierarchical Bayesian modeling of temporal trends in return levels for extreme precipitations. Korean J Appl Stat. 2015;28:137-49.

4. Ruimei C, Zebin L, Wenfa X, Quanshui G, Yanhui W, Na W, Yarui W. Leaf gas exchange, chlorophyll fluorescence, non-structural carbohydrate content and growth responses of Distylium chinense during complete submergence and subaerial re-emergence. Aquat Bot. 2015;124:70-7.

5. Voesenek $L A C J$, Sasidharan R. ethylene and oxygen signaling-drive plant survival during flooding. Plant Biol. 2012;15:426-35

6. Vu HTT, Manangkil OE, Mori N, Yoshida S, Nakamura C. Submergenceinduced $\mathrm{ADH}$ and $\mathrm{ALDH}$ gene expression in japonica and Indica rice with contrasting levels of seedling vigor under submergence stress. Biotechnol Eq. 2009:23:1469-73.

7. Das KK, Pandaa D, Sarkar RK, Reddya JN, Ismail AM. Submergence tolerance in relation to variable floodwater conditions in rice. Environmental and Experimental Botany. 2009;66:425-34.

8. Shunsaku N, Takaki Y, Hirokazu T, Lukasz K, Mikio N. Mechanisms for coping with submergence and waterlogging in rice. J Rice. 2012;5:2-14.

9. Debabrata P, Ramani KS. Mechanism associated with nonstructural carbohydrate accumulation in submergence tolerant rice (Oryza sativa L.) cultivars. J Plant Interact. 2015;9:62-8.

10. Sarkar RK, De RN, Reeddy JN, Ramakrishnayya G. Studies on the submergence tolerance mechanism in relation to carbohydrate, chlorophyll and specific leaf weight in rice. J Plant Physiol. 1996;149:623-5.

11. Ella ES, Kawano N, Ito O. Importance of active oxygen-scavenging system in the recovery of rice seedlings after submergence. Plant Sci. 2003;165:85-93.

12. Panda D, Sharma SG, Sarkar RK. Chlorophyll fluorescence parameters, $\mathrm{CO}_{2}$ photosynthetic rate and regeneration capacity as a result of complete submergence and subsequent re-emergence in rice (Oryza sativa L.). Aquat Bot. 2008;88:127-33.

13. Hattori Y, Nagai K, Furukawa S, Song XJ, Kawano R, Sakakibara H, Wu JZ, Matsumoto T, Yoshimura A, Kitano H, Matsuoka M, Mori H, Ashikari M. The ethylene response factors SNORKEL1 and SNORKEL2 allow rice to adapt to deep water. Nature. 2009;460:1026-31.

14. Cox MCH, Benschop JJ, Vreeburg RAM, Wagemaker CAM, Moritz T, Peeters AJM, Voesenek LACJ. The roles of ethylene, auxin, abscisic acid, and gibberellin in the hyponastic growth of submerged Rumex palustris petioles. Plant Physiol. 2004;136:2948-60.

15. Sarkar RK. Saccharide content and growth parameters in relation with flooding tolerance in rice. Biol Plant. 1998;40:597-603.
16. Almeida AM, Vriezen WH, Van der Straeten D. Molecular and physiological mechanisms of flooding avoidance and tolerance in rice. Russian J Plant Physiol. 2003;50:743-51.

17. Schmitz AJ, Folsom JJ, Jikamaru Y, Ronald P, Walia H. SUB1A-mediated submergence tolerance response in rice involves differential regulation of the brassinosteroid pathway. New Phytol. 2013;198:1060-70.

18. Xu K, Mackill DJ. A major locus for submergence tolerance mapped on rice chromosome 9. Mol Breed. 1996;2:219-24.

19. Fukao T, Yeung E, Bailey-Serres J. The submergence tolerance regulator SUB1A mediates crosstalk between submergence and drought tolerance in rice. Plant Cell. 2011:23:412-27.

20. Septiningsih EM, Bertrand CYC, Heuer S, Julia BS, Abdelbagi MI, David JM. Applying genomics tools for breeding submergence tolerance in rice. Trans Genomics Crop Breed. 2013;2:9-30

21. Sharma N, Dang TM, Singh N, Ruzicic S, Roeber BM, Baumann U, Heuer S. Allelic variants of OsSUB1A cause differential expression of transcription factor genes in response to submergence in rice. Rice. 2018;11:2-31.

22. Xiang J, Wu H, Zhang Y, Zhang Y, Wang Y, Li Z, Lin H, Chen H, Zhang J, Zhu D. Transcriptomic analysis of gibberellin- and paclobutrazol-treated rice seedlings under submergence. Int J Mol Sci. 2017;18(10):2225-41.

23. Hsu SK, Tung CW. RNA-Seq analysis of diverse rice genotypes to identify the genes controlling coleptile growth during submerged germination. Front Plant Sci. 2017:8:762-77.

24. Calvino M, Bruggmann R, Messing J. Screen of genes linked to high-sugar content in stems by comparative genomics. Rice. 2008;1:166-76.

25. Ntanos DA, Koutroubas SD. Dry matter and N accumulation and translocation for indica and japonica rice under Mediterranean condition. Fie Field Crops Res. 2002:74:93-101.

26. Bohnert HJ, Nelson DE, Jensen RG. Adaptations to environmental stresses. Plant Cell. 1995:7:1099-111.

27. Das KK, Sarkar RK, Ismail AM. Elongation ability and non-structural carbohydrate levels in relation to submergence tolerance in rice. Plant Sci. 2005;168:131-6.

28. Nagai K, Hattori Y, Ashikari M. Stunt and elongate? Two opposite strategies by which rice adopts to flood. J Plant Res. 2010;123:303-9.

29. Hirose T, Ohdan T, Nakamura Y, Terao T. Expression profiling of genes related to starch synthesis in rice leaf sheaths during the heading period. Physiol Plant. 2006;128:425-35.

30. Hwang JW, Kim SK, Lee JS, Kim IS. Gene expression of the biosynthetic enzymes and biosynthesis of starch during rice grain development. J Plant Biol. 2005:48:448-55.

31. Sturm A, Tang GA. The sucrose-cleaving enzymes of plants are crucial for development, growth and carbon partitioning. Trends Plant Sci. 1999;4:401-7.

32. Jing FU, Yunji XU, Chen LU, Yuan LM, Wang ZQ, Yang JC. Changes in enzyme activities involved in starch synthesis and hormone concentrations in superior and inferior spikelets and their association with grain filling of super rice. Rice Sci. 2013;20:120-8.

33. Salemo GL, Paqnussat GC, Pontis HG. Studies on sucrose-phosphate synthase from rice leaves. Cell Mol Biol. 1998;44:407-16.

34. Steven $\mathrm{CH}$, Joan LH. Role and regulation of sucrose-phosphate synthase in higher plants. Plant Physiol. 1996;47:431-44

35. Aoki N, Hirose T, Scofield GN, Whitfeld PR, Furbank RT. The sucrose transporter gene family in rice. Plant Cell Physiol. 2003;44:223-32.

36. Yang JC, Zhang J, Wang Z, Zhu Q. Activities of starch hydrolytic enzymes and sucrose-phosphate synthase in the stems of rice subjected to water stress during grain filling. J Exp Bot. 2001;52:2169-79.

37. Akihiro T, Mizuno K, Fujimura T. Gene expression of ADP-glucose pyrophosphorylase and starch contents in rice cultured cells are cooperatively regulated by sucrose and ABA. Plant Cell Physiol. 2005;46:937-46.

38. Kwaqoe Y, Kubo A, Satoh H, Takaiwa F, Nakamura Y. Roles of isoamylase and ADP-glucose pyrophosphorylase in starch granule synthesis in rice endosperm. Plant J. 2005;42:164-74

39. Su JC. Starch synthesis and grain filling in rice. Dev Crop Sci. 2000;26:107-24.

40. Fujita N, Mayumi Y, Noriko A, Takashi O, Akio M, Hirohiko H, Nakamura Y. Function and characterization of starch synthase I using mutants in rice. Plant Physiol. 2006;140:1070-84.

41. Park YJ, Nishikawa T, Tomooka N, Nemoto K. Molecular cloning and expression analysis of a gene encoding soluble starch synthase I from grain amaranth (Amaranthus cruentus L.). Mol Breed. 2012;30:1065-76.

42. Yang YJ, Kwon HB, Peng HP, Shih MC. Stress responses and metabolic regulation of glyceraldehyde-3-phosphate dehydrogenase genes in Arabidopsis. Plant Physiol. 1993;101:209-16. 
43. Seshadri S, Akiyama T, Opassiri R, Kuaprasert B, James KC. Structural and enzymatic characterization of Os3BGlu6, a rice- B-glucosidase hydrolyzing hydrophobic glycosides and $(1 \rightarrow 3)$-and $(1 \rightarrow 2)$-linked disaccharides. Plant Physiol. 2009;151:47-58.

44. Schluepmann H, Van DA, Aghdasi M, Wobbes B, Paul M, Smeekens S. Trehalose mediated growth inhibition of arabidopsis seedlings is due to trehalose-6-phosphate accumulation. Plant Physiol. 2004;135:879-90.

45. Kolbe A, Tiessen A, Schluepamann H, Paul M, Ulrich S, Geignberger P. Trehalose 6-phosphate regulates starch synthesis via posttranslational redox activation of ADP-glucose pyrophosphorylase. Proc Natl Acad Sci U S A. 2005;102:1118-23.

46. Mackill DJ, Amante MM, Vergara BS, Sarkarung S. Improved semidwarf rice lines with tolerance to submergence of seedlings. Crop Sci. 2010;33:749-53.

47. Septiningish EM, Pamplona AM, Sanchez DL, Neeraja CN, Vergara GV, Heuer $\mathrm{S}$, Ismail AM, Mackill DJ. Development of submergence-tolerant rice cultivars: the sub1 locus and beyond. Ann Bot. 2009;103:151-60.

48. Neeraja CN, Maghirang-Rodriguez R, Pamplina A, Heuer S, Collard BCY, Septiningsih EM, Vergara G, Sanchez D, Ismail AM, Mackil DG. A markerassisted backcross approach for developing submergence-tolerant rice cultivars. Theor Appl Genet. 2007;115:767-76.

49. Iftekharuddaula KM, Ahmed HU, Ghosal S, Moni ZR, Amin A, Ali MS. Development of new submergence tolerant rice variety for Bangladesh using marker-assisted backcrossing. Rice Sci. 2015;22:16-26.

50. Singh A, Carandang J, Gonzaga ZJC, Collard BCY, Ismail AM. Identification of QTLs for yield and agronomic traits in rice under stagnant flooding conditions. Rice. 2017:10:15-33.

51. Adak MK, Ghosh N, Dasgupta DK, Gupta S. Impeded carbohydrate metabolism in rice plants under submergence stress. Rice Sci. 2011;18:116-26.

52. Locke AM, Barding GA Jr, Sathnur S, Larive CK, Julia BS. Rice SUB1A constraints remodeling of the transcriptome and metabolome during submergence to facilitate post-submergence recovery. Plant Cell Environ. 2018:41:721-36.

53. Wei KS, Yang WL, Jilani G, Zhou WJ, Liu GK, Chaudhry AN, Cao ZZ, Cheng FM. Effect of high temperature on the enzymatic activities and transcriptional expression of starch debranching enzyme(DBE) multiple isoforms in developing rice endosperms. J Anim Plant Sci. 2012;22:97-107.

54. Lee HY, Hwang WH, Jeong JH, Ahn SH, Baek JS, Jeong HY, Park HK, Ku Bl, Yun JT, Lee GH, Choi KY. Change in yield and quality characteristics of rice by flooding during the ripening stage. Korea J Crop Sci. 2017;62(2):87-95.

55. Richard CL, Robert PW. Regulation and roles of phosphoenolpyruvate carboxykinase in plants. Biochem Biophys. 2003;414:204-10.

56. Kappachery S, Gangadhar BH, Yu JW, Park SW. Effect of over-and underexpression of glyceraldehyde 3-phosphate dehydrogenase on tolerance of plants to water-deficit stress. Plant Cell Tissue Organ Cult. 2015;121:97-107.

57. Jeong MJ, Park SC, Kwon HB, Byun MO. Isolation and characterization of the gene encoding Glyceraldehyde-3-phosphate dehydrogenase. Biochem Biophys Res Commun. 2000;278:192-6.

58. Chang S, Puryear J, Caimey J. A simple and efficient method for isolating RNA from pine trees. Plant Mol Biol. 1993;11:113-6.

59. Cox MP, Peterson DA, Biggs PJ. SolexaQA: at-a-glance quality assessment of Illumina second-generation sequencing data. Bioinfomatics. 2010;11:485-91.

60. Langmead B, Salzberg SL. Fast gapped-read alignment with bowtie 2. Nat Methods. 2012;9:357-9.

61. Anders S, Huber W. Differential expression analysis for sequence count data. Genome Biol. 2010;11:1-12.

62. Goodstein DM, Shu S, Howson R, Neupane R, Hayes RD, Fazo J, Mitros T, Dirks W, Hellsten U, Putnam N, Rokhsar DS. Phytozome: a comparative platform for green plant genomics. Nucleic Acids Res. 2012;40:1178-86.

63. Storey JD, Tibshirani R. Statistical significance for genomewide studies. PNAS. 2003;16:9440-5.

64. Ashburner M, Ball CA, Blake JA, Botstein D, Butler H, Cherry JM, Davis AP Dolinski K, Dwight SS, Eppig JT, Harris MA, Hill DP, Issel-Tarver L, Kasarskis A, Lewis S, Matese JC, Richardson JE, Ringwald M, Rubin GM, Sherlock G. Gene ontology: tool for the unification of biology. the gene ontology consortium. Nat Genent. 2000;25:25-9.

65. Lucas A. amap: Another multidimensional analysis package; 2014.

Ready to submit your research? Choose BMC and benefit from:

- fast, convenient online submission

- thorough peer review by experienced researchers in your field

- rapid publication on acceptance

- support for research data, including large and complex data types

- gold Open Access which fosters wider collaboration and increased citations

- maximum visibility for your research: over $100 \mathrm{M}$ website views per year

At BMC, research is always in progress.

Learn more biomedcentral.com/submissions 